\title{
Liberación-sin más: ¿Una discusión deslavada? Re-lectura en clave destructiva acerca de la filosofía en Latinoamérica
}

\section{Liberation - just it: A fading discussion? Rereading in destructive key about philosophy in Latin America}

\author{
Mauricio Suil Cerda*
}

Recibido: 25/04/2013 · Aceptado: 22/07/2013

\begin{abstract}
Resumen
Si la interrogante en torno a la autenticidad de la filosofía latinoamericana se ha proyectado en un repliegue teorizantemente academicista e institucional como síntesis de la tensión liberación-sin más, es algo que puede apreciarse desde una mirada directa al debate Salazar Bondy-Zea. El camino trazado para un pensar realmente histórico, sin adjetivos, rigurosamente crítico y radicalmente liberador, se aplica sobre la base de cierta tradición investigativa que sigue siendo el referente de las ideas filosóficas, razón por la cual permanece funcionalmente enajenada en el perfil especulativo inherente a la racionalidad moderna, base de un discurso igualmente dominador. Desde la 'clave destructiva' es posible apreciar esta inflexión que tiende a soslayar el análisis rupturista como posibilidad reflexiva, y con lo que parte importante del filosofar queda sujeto a estructuras que lo desenfocan de su quehacer radicalmente cuestionador y problemático.
\end{abstract}

Palabras clave: Filosofía - destrucción - enajenación - liberación - 'sin más'

\begin{abstract}
This article examines the authenticity of Latin American philosophy from the debate between Augusto Salazar Bondy and Leopoldo Zea. This debate is an academic and institutional theoretical synthesis of the "simply, liberation" tension; the discussion is permeated by the speculative profile of modern rationality. From a destructive approach, this article explores this turning point which usually sidesteps the breaking-up analysis and its reflexive possibilities; in this way, an important part of philosophising is subject to certain structures which get it out of its problematic and enquiring focus.
\end{abstract}

Key words: philosophy - breaking-up analysis - alienation - liberation "without more ado" 


\section{El porqué}

El presente texto es una revisión ${ }^{1}$ crítica de la conocida discusión entre Augusto Salazar Bondy y Leopoldo Zea: episodio relevante y uno de los eslabones centrales de la filosofía latinoamericana en vistas a su autocomprensión en la línea de su estatus existencial. Por cierto medio siglo ha pasado y una vasta producción en torno a este tema se ha hecho², por lo que es más fácil verla como controversia filosófica del pasado; luego, este trabajo podría parecer un escrúpulo semántico de interés conservador. Porque, si tal como decimos, en algún tiempo fue importante, ¿cuál es el sentido de volver hoy sobre este debate? ¿Es acaso la autenticidad de la filosofía latinoamericana un tema deslavado? ¿Cómo no progresar directamente desde la literatura especializada?

Hablar de 'destrucción como tarea' parece casi anacrónico, con sede en un punto del pensar latinoamericano que la asumió en la línea de la des-enajenación y liberación sociocultural. Sin embargo, creo que se debilitó paulatinamente su explicitación como problemática transversal a nuestra historia latinoamericana. Recepcionándose como mera autodefinición teorética, se ha ido imponiendo el rigor investigativo por sobre el vigor liberador.

Sin querer pasar por alto los brillantes trabajos a este respecto y sin pretender desconocer su importancia, este artículo quiere (re)hacerse cargo del problema, pues afecta directamente a la autenticidad como conflicto fundamental de un pensamiento latinoamericano cuyas características hoy se constituyen desde la interculturalidad; se busca llegar aquí a algo transversalmente histórico, latente como elemento legítimo de diálogo y no mera traspolación forzada de una polémica otrora importante. Se pretende indagar en las bases discursivas que

1 El énfasis del prefijo sugiere reforzar la idea de que este tema suele consignarse en gran parte concluido y salvado, ultra-tratado; una cuestión desgastada sin nuevas proyecciones. No debiera, eso sí, olvidarse que su impacto a fines de la década de los 60 llamó poderosamente la atención del quehacer filosófico, por lo que se considera uno de los momentos fundantes de la filosofía latinoamericana. Hoy llama la atención su abandono como pregunta fundamental acerca de nuestro pensar.

2 Cfr. CERUTTI, Horacio, Filosofía de la Liberación Latinoamericana, Fondo de Cultura Económica, México, 2006, pp. 263-273. 
guiaron el entrecruce de ambas posturas hacia la relectura de éstas como curvatura paradigmática; como influjo que determina la 'estabilidad crítica'. La propuesta de este estudio es apostar a una nueva pertinencia hermenéutica para este capítulo de la filosofía en América Latina, posible a través de la lectura en clave destructiva.

Intentar rescatar esta noción parece además riesgoso para el encuentro intercultural, frente al que se presentaría como disfuncionalidad o desajuste temático. Esto porque los pilares del diálogo parecen erigirse sobre los acuerdos, las búsquedas de puntos en común y el horizonte de la 'construcción' cultural, no en un empeño por destruir³. Si se trata o recoge descuidadamente el dinamismo destructivo del pensamiento, dejamos tal dinámica a merced de vicios in-comunicativos que evitan trasparentar aquello que nos mueve. Más aún, desde el uso y abuso de la palabra en las redes informativas oficiales ${ }^{4} y$ en el discurso conservador academicista, no tiene mucho lugar hablar de 'identidad destructiva de la filosofía'; asusta, desconcierta y se opta por marginar este concepto que no cumpliría con la misión transformadora de la sociedad y del pensamiento.

Siendo el reduccionismo en Latinoamérica un peligro latente, no es menor tomar ciertas precauciones teóricas como las que estamos haciendo. De entre las variables reduccionistas podríamos vislumbrar al menos dos extremos que se asoman al querer visibilizar la destrucción como pertinencia reflexiva-cultural: 1) una lectura acrítica de este concepto podría desembocar en una justificación extrema de los atentados contra toda estructuración comunitaria, incluso hacia las personas como única vía para provocar cambios socioculturales, y 2 ) a su vez, la idea de destrucción (bajo la forma de actitud crítica, resistencia social, exigencia de justicia, denuncia de la desigualdad,

3 En último caso estamos más acostumbrados a aceptar cierta metodología de-constructiva o des-constructiva, pero son conceptos usados como atenuante metodológico-constructivo.

4 Podemos recordar, por su mención explícita en su acusación, aquel episodio sucedido a partir de las movilizaciones estudiantiles de 2011, donde el presidente de la Central Unitaria de Trabajadores culpabiliza a los profesores de filosofía: Mercurio, D. E, Miércoles 31 de agosto de 2011. Recuperado el 14-07-2012, de emol.cl: http:// www.emol.com/noticias/nacional/2011/08/31/500735/arturo-martinez-culpa-a-losprofesores-de-filosofia-por-violencia-en-las-marchas.html. 
etc.) provoca repliegues conservadores de intolerancia que la declaren peligrosa para el orden y la paz ciudadana.

Aun cuando conlleve cierto riesgo en vistas a comprender la condición histórica-cultural de nuestro continente, el pensar destructivo se torna relevante para una lectura estructural del devenir histórico en Latinoamérica, desmantelando los modos de implementar un sistema que se establece como discurso hegemónico de pensamiento único, impuesto, sin alternativas. Desde la perspectiva productivista inherente a la omnipresencia del mercado, lo que caracteriza a la sociedad actual es un 'repliegue constructivo' de la cultura y la institución científico-intelectual a su servicio como pensamiento oficial, por lo que podríamos preguntar si la filosofía participa de ello como enajenación racional y si este debate acaecido a fines de los años 60 incide en la pérdida de su horizonte. Buscar una respuesta a esta cuestión desde la dialéctica entre los autores señalados presupone no sólo una revisión cuidadosa, sino redescubrir el sentido de la labor destructiva como posibilidad de 'pensar auténtico' y 'sin más'. De manera que podemos darle a esta faceta de la filosofía un lugar pertinente de diálogo en medio del escenario provocado por el 'desarrollo globalizado', la crisis de la institucionalidad y del papel que le cabe al conocimiento y al saber en medio de éstas.

Retrotraemos la mirada hacia 1968. La interrogante sobre la autenticidad del pensamiento latinoamericano adquirió un énfasis especial cuando Salazar Bondy publica su libro ¿Existe un filosofía en nuestra América?, en el que confiere a la 'destrucción' el rol principal de abrir la única alternativa para que el pensamiento y la cultura americana renuncien a su condición alienada e inauténtica. Al año siguiente Leopoldo Zea escribe La Filosofía americana como una Filosofía sin más, donde retoma la pregunta e intenta responder con una posición más amplia, rectificando algunos puntos de la posición de Salazar Bondy, especialmente en lo relativo a la destrucción cultural como tarea de la filosofía. El punto de conflicto es esa identidad destructiva; tal vez sea difícil hallar otra discusión más directa que ésta.

\section{Salazar Bondy y la labor destructiva como principal tarea filosófica}


Fue 1968 un año convulsionado a nivel de política internacional, entre otros por la revolución universitaria-sindical del Mayo Francés y el trágico episodio de la matanza de Tlatelolco en contra de un grupo de manifestantes, la mayoría de ellos estudiantes de nivel medio superior de la UNAM-IPN. Pese a la situación de desigualdad y colapsos políticos, América busca alternativas de una vida más justa y digna, poniendo la esperanza en el poder de cambio que poseen las nuevas ideas, emergiendo con fuerza los diversos movimientos de liberación. El paradigma liberador ejerce su influjo en los movimientos sociales, y también en Salazar Bondy. La estructura de su texto responde a la contingencia desde una matriz dialéctica, especialmente hegeliano-marxista.

Como ya lo enunciamos, describe la condición de nuestro pensamiento americano caracterizado por su in-genuidad imitativa en lo fundamental, revelando que pensamos alienadamente, ademas de querer mostrar algo que no estamos llamados a ser: una identidad que no responde a lo más propio de nuestra realidad. La causa determinante de este hecho es la existencia de un defecto básico que se traduce en un existir alienado por el subdesarrollo, la dependencia y la dominación. Lo que siempre nos ha tocado vivir como continente es la regeneración de un mecanismo que reproduce la alienación en todas sus formas culturales, valóricas, institucionales y tradicionales.

Así, el sentido de nuestra organización sociocultural se ha ido tornando extraño, porque en nuestras comunidades prevalece la mistificación y la ficción, principalmente a nivel de las instituciones, las cuales poseen un signo distinto del que declaran. Las formas de conducta, las relaciones intersubjetivas, las costumbres, todos caen en esta "entidad ambigua, en este funcionar y estar motivados de modo contrario al que pretendidamente les corresponde" ${ }^{\prime}$, especialmente la Democracia, la Universidad o el Estado. Estas entidades representan tales contradicciones vitales, pues son movidas por intereses ajenos y códigos de conducta que tendemos a imitar sin poder contemplar en absoluto la cruda situación de miseria, las masas pauperizadas que 
crecen día a día sin detenerse. Este producto humano inauténtico y enajenado se expresa en las mismas autodefiniciones con las que pretendemos reflejar nuestra condición, tales como "occidentales, latinos, modernos, católicos y demócratas, dando a entender con cada una de estas calificaciones... algo distinto a lo que en verdad existe" ${ }^{\prime 6}$. Nuestra pseudo-identidad no es más que el resultado de la sujeción a otros intereses ajenos que nos han subyugado siempre desde siglos.

La existencia de una auténtica filosofía latinoamericana -afirma Salazar Bondy- está en íntima relación con la situación socioeconómica de nuestro continente. Nuestra filosofía fue un pensamiento impuesto por el conquistador europeo de acuerdo a los intereses de la Corona y de la Iglesia, luego pasó a ser "un pensamiento de clase dirigente o de elites oligárquicas refinadas y ha correspondido generalmente a olas de infuencia económico-política extranjera"7, es decir, con el sello de la dominación. Esa precariedad político-económica nos hace "una novela plagiada y no la crónica de nuestra aventura humana" 8 . El pensador hispanoamericano es un constante frustrado ante "la imposibilidad de vivir según los patrones culturales extranjeros y en la incapacidad simultánea de hacer fecunda en el pensamiento la vida de la comunidad estancada" ${ }^{\prime \prime}$.

Para lograr un pensamiento genuino y original se necesita la transformación social decidida mediante la cancelación del subdesarrollo y la dominación, propio de naciones como las nuestras, pertenecientes al Tercer Mundo. Esto implica forjar una filosofía propia que contraste con las concepciones generadas desde los grandes bloques de poder. El advenimiento de la liberación, como de una nueva sociedad auténtica por medio de una radical forma de redescubrirnos, se hace en el aquí y ahora, en nuestra existencia concreta que se prepara en la lucha histórica. Salazar Bondy repara en que esto no será fácil e intuye que la mantención del carácter imitativo durará aún más tiempo, ante lo cual debemos ser vigilantes y desconfiados en extremo para no caer en el producto intelectual alienado. 
De esto podemos concluir la urgencia de pensar auténtica y creativamente para alcanzar una filosofía original, porque la filosofía sólo será genuina en la medida que sea expresión de una sociedad con identidad creadora, en tanto conciencia de la mutación histórica inevitable.

Es en la tercera parte de la obra citada donde encontramos el aporte propio de Salazar Bondy a la filosofía americana y su referencia explícita al proceso destructivo: "una buena parte de la tarea que tiene por delante nuestra filosofía es destructiva -a la larga destructiva también de su entidad actual como pensamiento alienado...- [por lo que su única salida es] ser una conciencia canceladora de prejuicios, mitos, ídolos... apta para develar nuestra sujeción como pueblos y nuestra depresión como seres humanos"10. En tanto que el problema de nuestra filosofía es la inautencidad enraizada como países subdesarrollados y desposeídos, su posibilidad está en lograr esta condición radicalmente antitética que propicia y abre las puertas a nuevas formas de comprensión antropológica y cultural. De modo que no es posible un libre-pensar ni un pensar-libre mientras tengamos la sombra de las expresiones culturales modernas provenientes de los países que nos han sometido por siglos.

El modo peculiar de entender tal actividad destructiva no debe confundirse con la pura praxis sociológica, sino que se expresa en ser "conciencia lúcida de nuestra condición deprimida como pueblos y en el pensamiento capaz de desencadenar y promover el proceso superador de esta condición... una reflexión sobre nuestro status antropológico"11, del cual nos hacemos conscientes en vistas a terminarlo. Es relevante el hecho de que la toma de conciencia comienza desde nuestra misma realidad humana individual y colectiva, pues se trata de una reflexión "siempre antropológicamente relevante como autoanálisis"12. La destrucción filosófica comienza ante todo por retrotraernos y mirar la propia tradición y el origen histórico de nuestra condición. Luego, el camino será acabar con todos los elementos provenientes de los poderes mundiales que nos mantienen en la depresión constante y la miseria a todo nivel. Jamás hemos desarrollado como

$10 \quad$ Ibíd, p. 126.

11 ld.

12 Id. 
americanos una existencia auténtica, y atrevernos a 'ser' es arrojarnos por tanto al quiebre profundo con el paradigma dominante validado en todas las esferas socioculturales.

\section{Leopoldo Zea y la labor filosófica como 'un filosofar sin más'.}

El mismo escenario mundial y nacional de la década, además de la discusión filosófica, impulsan al filósofo mexicano a elaborar al año siguiente una respuesta en vistas a corregir y precisar algunos planteamientos hechos por Salazar Bondy. En lo fundamental concuerda con él en que la filosofía latinoamericana se desarrolló a partir de una situación de imposición y subordinación cultural. Zea se opone a una filosofía que repite el proceder de los grandes sistemas europeos, sin embargo, no está de acuerdo con quienes -como el mismo Salazar Bondy- se muestran pesimistas frente a la existencia o posibilidad de una filosofía en América; no hemos dejado de tener filosofía al no haber construido reflexiones al modo de los sistemas clásicos. Señala que en el caso de América Latina, el filosofar ha pasado de la inautenticidad original a la 'autenticidad de la asimilación'. Las distintas formas de desarrollo del pensamiento latinoamericano no se traducen en una falta de nivel y rigor intelectual, pues debemos entender más bien que nuestra labor filosófica es pura y simplemente filosofar 'sin más', luego, podríamos decir que lo americano viene consecuentemente por añadidura. De tal manera que la filosofía, hundiendo sus raíces en sus modos característicos de cultura que son resultado de su devenir propio, debe articularse desde la realidad histórica que le ha tocado comprender, lo que posibilita un sentido específico de originalidad que no repite problemas ajenos.

La tendencia de Zea es más bien a superar el paradigma de la confrontación total, centrándose en lo humano como principio y origen común de la filosofía universal: la filosofía en América surge ante todo como problema humano, pues en la relación con el Logos ordenador aparece de un modo más especial el 'filósofo', aquel hombre que hace de ese instrumento su virtud existencial: "es el hombre que quiere 
saber del ser en la nada, del orden en el $\operatorname{caos}^{\prime 13}$. Tanto Latinoamérica como Occidente tropiezan con el individuo colonizado que también puede leer la realidad. Así, el occidental se da cuenta de sus limitaciones y de que el latinoamericano también es humano-pensante.

En este hombre-logos americano se revela un preguntar singular, una especie de pregunta especial que nos configura originalmente. Es aquí donde se descubre el problema de la inautenticidad para Zea, pues un cierto 'preguntar' nos fue impuesto como Historia Universal, desde una expansión agresiva de un humanismo que creó el conflicto entre lo Humano y lo (no-humano) que había en América. Pertenecer a la Humanidad implicaba encajar en determinado arquetipo: "Europa occidental y Estados Unidos serán el modelo a alcanzar en el campo cultural y filosófico, como será también el ideal del hombre a alcanzar"14, de ahí se deriva nuestro pensar caracterizado por esta subordinación originaria.

El enfoque de Zea, ya lo dijimos, no es confrontacional ante las expresiones provenientes de los centros de poder mundial, e insiste que no se trata de ser original por moda: en este empeño se han logrado expresiones excéntricas que han hecho "todo menos filosofía"15. Al parecer no hemos logrado reconocer que la interrogante en torno a la posibilidad de una filosofía en América es la posibilidad misma de esa pregunta. Al hacer consciente la interrogante en torno a la filosofía americana ya estamos "haciendo una filosofía que parte de nuestra problemática"16, pero generalmente no descubrimos al hombre por debajo del sub-hombre con que se nos ha querido calificar, sino que "seguimos buscando al hombre por encima de sí mismos, de nuestra propia realidad, de lo que somos, de lo que hemos sido y de lo que podemos seguir siendo"17. La originalidad reflexiva no se alcanzará si nuestro empeño se enfoca en crear sistemas metafísicos que no sean el resultado de una necesidad vital sin prejuicios ni imposiciones.

13 ZEA, Leopoldo, La Filosofía Americana como Filosofía sin más, Siglo XXI Editores, México, 2010, p. 10.

14 Ibíd., p. 20.

15 Ibíd, p. 45.

16 Ibíd, pp. 105.

17 Ibíd, pp. 104. 
La acción de copiar es constitutiva universal del pensamiento, en ella dejamos nuestra propia huella. De tal manera que la filosofía europea puede adaptarse y retorcerse a la realidad que es llevada, pero su adopción no produce mágicamente las mismas circunstancias europeas. Al querer hacer una filosofía original se ha olvidado al hombre mismo, cayendo en modelos que nos hacen deudores de una técnica instrumentalizadora-productiva. Haciéndonos cómplices de mecanismos de postergación y subdesarrollo, hemos reducido la filosofía a las promesas de vanguardia técnica, a su precisión y excelencia que encarcela a la naturaleza. Demás está decir que tales fines y logros no han bastado "para poner fin a situaciones humanas que se mantienen como en la Edad de las Cavernas"18, creando enfrentamientos depredadores, haciendo que el hombre siga siendo un 'lobo para el hombre'.

Respecto a la destrucción misma, referida en el capítulo 5 y más especialmente en el capítulo 6 de su libro, Zea la deja entrever en el rol histórico de los hombres que construyen la sociedad, que sienten su libertad, que no se han enajenado y rompen con todo impedimento que atenta contra la vida humana: esa es la historia de Latinoamérica.

Evalúa las influencias de otras filosofías destructivas no nacidas en América, especialmente Fanon, Sartre y Trotignon. Rechaza la acogida lisa y llana de ningún modelo destructivo, pues significaría asumir imitativamente no solo ideas, sino épocas con sus procesos que se repiten y no son los nuestros. Desde la perspectiva del colonizado no es preciso terminar íntegramente con la cultura heredada, sino evitar que se mantenga la dominación: "La víctima no tiene necesidad de destruir el mundo de su victimario, le bastará impedir que este mundo mantenga la subordinación por él establecida. Pero, naturalmente, si este impedimento anula a su vez la existencia de ese mundo, su destrucción plena es ya algo secundario"19. Los latinoamericanos llevamos una dirección distinta a los europeos; ellos en su culpabilidad pretenden destruir la culpa de su historia, nosotros en cambio, tenemos una historia a partir de la cual no estamos llamados a aniquilar lo que hemos logrado sobrellevar a lo largo de los siglos. Más que re-adaptar 
la cultura europea, se debe 'destruir ciertos rasgos culturales' de la cultura occidental burguesa que se impone en América: no empezar de cero por la moda de seguir a Europa.

De manera que Zea no se cierra al proceso destructivo, pero aclara: "¿Destruir? Sí, lo que limite la dignidad del hombre, no una dignidad abstracta sino concreta, no importa quién sea el autor de esta limitación" ${ }^{\prime 20}$. Advierte que la destrucción no puede ser creadora de nuevas trampas históricas que nos aten nuevamente; se debe destruir "no para crear nuevas limitaciones, sino para evitar que vuelvan a repetirse" ${ }^{21}$. Hay que tener cuidado de que el filosofar destructivo caiga en una filosofía de la supuesta acción y no un reflexionar para actuar, porque muchas veces esos son los anhelos de una cultura que no es la nuestra.

Hacia el final de su libro, retoma directamente las tesis de Salazar Bondy. Especialmente lo refuta cuando éste "liga el problema de la inautenticidad de la filosofía, y la misma cultura latinoamericana al problema del subdesarrollo..." ${ }^{22}$. Para Zea la autenticidad de nuestra filosofía no puede provenir de la superación del deterioro estructural económico, sino que proviene de "nuestra capacidad de enfrentarnos a los problemas que se nos presentan hasta sus últimas raíces, tratando de dar a los mismos la solución que se acerque más a la posibilidad de la realización del nuevo hombre"23. Incluso contempla la posibilidad de una revolución, pero sólo desde la "previa autenticidad de nuestro pensamiento sobre la realidad que debe ser transformada" 24 , y añade que "la autenticidad no es consecuencia directa de tal revolución social, política y económica, sino la base de su posibilidad"25. Auténtica no sólo es la filosofía que instaura un nuevo modo de con-vivencia social, sino la que hace "consciente nuestro subdesarrollo y señale las posibilidades de su vencimiento y la forma como vencerlo"26. Es posible la filosofía auténtica en el desarrollo y en el subdesarrollo, en cualquier

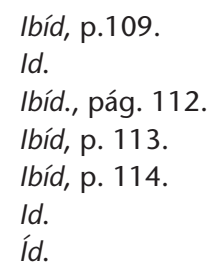


fase del camino de lo humano hacia su plenitud, hacia su liberación.

Insiste el filósofo mexicano respecto a la posibilidad de una filosofía americana que "no sólo es posible sino que lo ha sido o lo es, independiente de la forma que la misma haya tomado" 27 , sea auténtica o inauténtica: en lo que haya sido posible realizar está la base de lo que se quiere seguir realizando, pero debemos tomar distancia del pensar que nos ha sido impuesto y que destruye buscando el punto cero, enajenándose en los medios y en los fines.

\section{Paralelos}

Curiosamente, para los efectos de este trabajo en torno a una 'idea destructiva', la primera concordancia entre nuestros autores reside en la búsqueda de la construcción cultural. Nos dice Salazar Bondy que tal confrontación y ahondamiento en nuestra condición subyugada tiene un horizonte creador y constructivo. Zea por su parte recuerda que "nuestro problema no es destruir sino construir" ${ }^{28}$. Además, menciona la necesidad de ir creando nuevos modos de presentar una filosofía que no se capitaliza en pura teoría, sino que se manifiesta como expresión múltiple de los pueblos no desarrollados. Parece concordar con Salazar Bondy, eso sí, en el advenimiento de una "filosofía de la acción encaminada a subvertir, a cambiar un orden en el que la auténtica esencia del hombre ha sido menoscabada" ${ }^{29}$. Se trata de una filosofía que apunta a la universalidad de lo humano "una filosofía sin más del hombre y para el hombre, en donde quiera que éste se encuentre" ${ }^{\prime 30}$.

Coinciden en lo general, a saber, que nuestra filosofía se ha desarrollado desde la interposición externa, desde nuestra condición reducida a la categoría 'sub-humana'. El origen de la conquista instaura la alienación antropológica desde donde se construye aquella cultura que enajena nuestra condición humana. Estarían de acuerdo en que no logramos generar razonamientos auténticos coherentes con nuestra 
realidad, por cuanto entramos en la estructura marginadora donde el Logos (esencial para que el ser humano concrete las grandes ideas en la historia) no nos es inherente ni está a nuestro alcance, lo que hace mucho más difícil el surgimiento del 'filósofo'.

Además, ambos tienen similar modelo de recuperar la originalidad reflexiva. Salazar Bondy señala que nuestro pensamiento debe generarse en función de captar y anular la situación humana en la que nos encontramos envueltos, tomando conciencia de que la propia condición decaída radica en la situación inhumana de la sociedad y cultura americanas, una situación de abismante deterioro de la vida e indignidad por la ausencia de los derechos humanos, que crea y recrea mistificaciones autocomprensivas, observables en actos como el naturalizar la miseria, la desigualdad y la injusticia, participando siempre en una categoría inferior de los avances y progresos económicos del desarrollo mundial. En el mismo sentido, Zea señala que se debe destruir todo aquello que atente contra la dignidad del hombre y de Latinoamérica, ya que la labor de una destrucción debe rescatar la condición negada de pueblo consciente.

Salazar Bondy dice que la filosofía hispanoamericana no tiene tradición propia y ha comenzado a partir de una filosofía europea extraña que se proyecta en una evolución paralela, por lo que surge la necesidad de hacer una filosofía hispanoamericana que avance no desde una dinámica externa sin previa gestación que siempre está en desfase con las corrientes de las grandes naciones, sino que se despliegue en dirección destructiva de los rasgos que desfiguran nuestra fisonomía: el sentido imitativo de la reflexión, la receptividad universal como una recepción acrítica del producto teórico europeo, la superficialidad y pobreza del filosofar, entre otros. Zea señala también que la nuestra es la historia de un pensar subordinado, que se debe derribar aquello que no sea afín con nuestra propia historia, porque aun cuando hablemos del hombre y sociedad nueva, no debemos seguir haciendo patente el peso de Europa y el de Occidente. Ahora bien, si todo esto puede concretarse en el horizonte de las formas culturales heredadas de otras tradiciones, es un punto en el cual Zea presenta sus diferencias con Salazar Bondy. Por cierto que los matices que utilizan ambos para articular la labor destructiva de la filosofía son distintos y hasta cierto punto paralelos. Es lo que trataremos de precisar mejor bajo el 
sello destructivo.

Zea trata vastamente el tema de la destrucción, en cambio Salazar Bondy le dedica expresamente algunas líneas, aunque bastan esas breves menciones para verla presente en toda su teoría. El contraste entre las dos tesis aparece de manera general en el 'cómo' recuperar el sentido genuino de nuestra condición americana.

Para llegar a esto, Salazar Bondy concede suma importancia a un quiebre radical con la tradición, confiriéndole a la filosofía el sentido de antítesis del pensamiento establecido. En cambio Zea, persiguiendo los mismos fines, cree en que es posible adoptar patrones externos desde la originalidad imitativa; sustenta la tesis de que las ideas provenientes de afuera no son intrínsecamente nocivas.

Salazar Bondy afirma que una buena parte de la tarea de la filosofía es destructiva de su entidad actual como pensamiento alienado, y para ello recurre a la radicalidad de acabar con todo lo enajenante de la cultura actual; se debe asumir la condición en la que nos encontramos, alienada en todas sus formas y signo eminentemente negativo que debe ser superado. La identidad del pensamiento americano se logra en la liberación de todo lo que nos hace vivir una realidad ajena, falsa, que nos relega a una decadencia permanente sin futuro, trabas impregnadas en la totalidad de nuestras expresiones sociales y culturales. Por eso debemos ser artífices de la esencia propia de nuestro pensar, constituido diametralmente opuesto al curso de cómo ésta se da en el Primer Mundo. Pareciera que desde esta perspectiva hay pocas cosas rescatables en América, lo que exige la ruptura total con los lazos de dominación. El pensamiento genuino, para Salazar Bondy, debe oponerse y abstenerse de todo crédito hacia las construcciones o fuentes intelectuales que se nos ha legado.

Zea no está de acuerdo en tomar este modelo destructivo acríticamente ni de manera tan extrema; no nos corresponde repetir temáticas lógicas y existenciales como la desesperación y la náusea ante una sociedad que ha enajenado al hombre que la hizo posible. Cree que la necesidad de destrucción al modo de Salazar Bondy es imitativa en sí, una repetición de épocas y procesos históricos que no son los nuestros. Latinoamérica no tiene por qué autodestruirse; si nuestra condición ha sido el padecer las imposiciones forzadas, no podemos 
desprender de eso la necesidad de destruir todo lo que tenemos, aun cuando haya sido promovido desde la violenta conquista y colonización. Porque para Zea, aun cuando reconoce la destrucción como proceso, la filosofía es entrar en una dinámica constructiva, que es lo que realmente necesitamos como pueblo. Se contrapone a Salazar Bondy, pues piensa que polarizar la actividad filosófica se desvía de la búsqueda de nuestra verdad; no debemos desechar todas las formas e ideas filosóficas, aunque vengan de quienes siempre nos han mantenido sujetos a sus intereses, pues lo importante es filosofar sin agregados, sin que en su esencia exista el añadido intrínseco de oponerse diametralmente a todo.

El diagnóstico de la filosofía americana desde esta postura es más alentador, considerando que nuestras formas de filosofar se han expresado, aunque no en grandes sistemas, de muchas otras formas: máximas, poemas, ensayos, piezas teatrales o una novela. Por lo mismo nuestra creación debe ser en función del 'construir-nos', independientemente de si usamos categorías o referencias a filósofos de otros lugares, pertenecientes a otro tiempo o cultura. Destruir todo y empezar de cero constituye para Zea la alienación denunciada, pues sería sacar fuera lo que somos: nuestra historia total que nos marca y nos da el carácter que tenemos, no construido sobre una base ideal, pero que es nuestra única posibilidad de dignificación y apertura hacia nuevos caminos como continente.

\section{Una Interpretación}

a) Otras aproximaciones sobre el debate: Para Fornet-Betancourt la novedad de Salazar Bondy es que logra esbozar las líneas del pensamiento latinoamericano para apuntar hacia una 'filosofía de la liberación'; el momento destructivo no debe estar en un primer plano de relevancia, sino el de la inculturación como crítica al eurocentrismo ${ }^{31}$. En esta dirección, Cerutti señala que posturas como la de Salazar Bondy constituyen un 'antimodelo paradigmático', un modo estandarizado de representar

31 Cfr. FORNET-BETANCOURT, Raúl, en Incidencia de la Teología de la liberación en la Filosofía Latinoamericana, y también en el texto De la significación de la filosofía latinoamericana para la superación del Eurocentrismo. 
la historia de la filosofía, la cual bloquea y obstaculiza dramáticamente los avances de la reflexión, impide filosofar y no es acorde al desarrollo histórico filosófico, planteando su posición en campos antagónicos extremos: o autoctonismo o filosofía como producto esencialmente occidental, quedándonos casi sin memoria histórica ${ }^{32}$. Desde el panorama propuesto por Santos Herceg, primeramente la disputa tratada es una discusión añeja y desperfilada ${ }^{33}$. El diagnóstico pesimista de una sociedad 'mal formada' hecho por Salazar Bondy sólo se enmarca como uno de los cuatro modos de 'decir filosofía latinoamericana'; su proyección destructiva está al interior de la forma específica que asume la filosofía 'en' nuestro continente; es sólo un 'momento' remoto junto a otros ${ }^{34}$ que, en su conjunto, grafican la perspectiva o la síntesis más completa de la posibilidad de hablar de filosofía latinoamericana. De todos modos conviene señalar que Santos Herceg, al interior de este sentido conceptual sostenido, es un filósofo capaz de arriesgar afirmaciones en una línea teórico-destructiva bastante acorde con la actitud propuesta por Salazar Bondy en el planteamiento de una crítica radical a la inautenticidad filosófica, especialmente cuando la caracteriza al ejercicio filosófico como uniforme, eurocéntrico y conservador ${ }^{35}$.

Especial mención merece Adriana Arpini, quien se ha preocupado de esta polémica, realizando un profundo análisis de la misma bajo la revisión crítica del historicismo; su estudio muestra el modo como se despliegan o entran en juego otras corrientes tales como la filosofía

32 Cfr. CERUTTI, Horacio, Filosofar desde Nuestra América, publicaciones de la Universidad Autónoma de Nayarit, en http://www.olimon.org/uan/cerutti2.pdf.

33 Cfr., ¿Qué se dice cuando se dice filosofía latinoamericana?, en Revista de Filosofía de la Universidad de Chile, Volumen 68 (2012), pp. 65 - 78.

34 Las otras versiones junto a 'la filosofía en América Latina' son: una filosofía para Latinoamérica; una filosofía cuyos temas son latinoamericanos y; hecha por sujetos latinoamericanos. Todas ellas, señala Santos, son englobadas por el sentido 'conceptual' de Filosofía Latinoamericana usado por Hugo Biagini. Dicho sentido conceptual engloba a los cuatro señalados, pues se relaciona con una filosofía propiamente latinoamericana y es referida a rasgos e inquietudes preponderantes que distinguen nuestro filosofar de otras expresiones nacionales. Cfr., Santos Herceg, José, Id.

35 Cfr. SANTOS HERCEG, José, Uniforme, Eurocéntrica y Conservadora. Un perfil de la enseñanza universitaria de la Filosofía en Chile, en Cuadernos CEPLA N ${ }^{\circ} 19$, pp. 92-135. Este lúcido y exhaustivo trabajo realizado por el profesor Santos Herceg se dirige principalmente a la enseñanza universitaria de la filosofía en Chile, lo que no necesariamente exime a toda la realidad académica latinoamericana. 
analítica, la teoría de la dependencia y los diferentes accesos al problema de lo ideológico, advirtiendo especialmente la importancia que implica esto para ampliar el ámbito teórico-metodológico de la Historia de las Ideas. Su crítica se propone ser imparcial y medular. Según ella, la debilidad de Zea es colocar los problemas relativos a la enajenación en el terreno de la conciencia, dejando en un segundo plano las diferencias (los conflictos, los momentos de negación, las rupturas del devenir histórico) por una visión armónica de la historia. Respecto de Salazar Bondy, además del clásico cuestionamiento a su 'punto cero', cree más bien que su principal dificultad radica en cómo llega a caracterizar negativamente la tradición hispanoamericana como producto intelectual alienado por el subdesarrollo y la dependencia: utiliza exclusivamente aquellas expresiones que representan un alto grado de especialización, propias de la producción académica 'normalizada'; el sujeto alienado es el intelectual en pos de las ideas de los centros mundiales dominantes, de modo que no logra superar su situación. Señala que el método analítico y su posición crítica frente al problema de lo ideológico (lo que permitió avances superadores de la hermenéutica clásica y le evitó caer en posiciones esencialistas) no le permitió al peruano superar la linealidad textual (la consideración del texto filosófico como expresión acabada de una única voz, sin considerar la complejidad del proceso de articulación de la trama textual). Valora eso sí, que Salazar Bondy nos haya colocado en las puertas de la problemática de la autenticidad y originalidad, sospechando de los síntomas de la acción de ideas filosóficas no-originales que no aportan a nuestra realidad ni poseen valor intrínseco suficiente, los que pueden constituir una instancia destructiva de prejuicios y constructiva de una nueva filosofía naciente ${ }^{36}$. Arpini por otra parte, sitúa a Salazar Bondy respecto a la dominación, señalando que para él, tal condición se supera bajo un ejercicio de 'imaginación utópica' en función de quebrar tal estructura dominante y así dejar emerger a otra históricamente diferente; así hace patente la relación entre

36 Cfr. ARPINI, Adriana, La polémica entre Augusto Salazar Bondy y Leopolodo Zea. Una revisión del historicismo en América Latina, en Otros Discursos: Estudios de Historia de las Ideas Latinoamericanas, Facultad de Ciencias Políticas y Sociales, Universidad Nacional de Cuyo, Mendoza, 2003, pp. 45-70. 
utopía y humanismo ${ }^{37}$, la que sustentaría cualquier labor destructiva posterior; se infiere que el sentido destructivo no estaría en sí mismo, sino supeditado a un paradigma ideológico concreto que integra categorías (dominación, liberación, etc.) que dan cuenta de los conflictos más urgentes, apelando a esquemas interpretativos que acentúan las contradicciones para dar paso a la emergencia de la novedad como evento de construcción histórica.

El punto de arranque particular tanto de Zea como de Salazar Bondy viene a constituir dos aportes de gran valor para el estudio y la metodología en el tratamiento de las ideas latinoamericanas como puerta de entrada a nuestra realidad. Más allá de si esta discusión se ejecuta desde matrices de análisis diferentes (no logran asumirse mutuamente o estableciendo una polémica auténtica), Arpini realiza interesantes planteos acerca de sus dificultades lógicas, influencias y alcances.

b) ¿Una discusión deslavada o soslayada?: En general, podríamos decir que todos estos planteamientos conceptualizan y definen con mayor rigor el estatus de una filosofía crítica y enfocada desde su propia realidad. Pero justamente es aquí donde vamos a arriesgar la tesis de que las ideas zeanianas, apoyadas en su enfoque historicista, tuvieron mejor intuición de esto, advirtiendo que un desenfreno rupturista nos coloca en una posición ciega que no logra ver las trampas instrumentales que nos hacen caer en la dominación denunciada, revelando serias y problemáticas deudas metodológicas.

Zea apunta a revalidar, mejorar, reinterpretar y ubicar en un reacondicionamiento prospectivo el sistema de evolución histórica de las ideas en América Latina. Su postura es más rigurosa y crítica; aporta un camino con más variables y alcances que busca resguardarse ante la seducción de paradigmas sutilmente impositivos. De hecho, los párrafos finales de La Filosofía Americana como Filosofía sin más son bastante afines con la invitación de Arpini a realizar "la tarea inexcu-

37 Cfr. ARPINI, Adriana, Utopía y Humanismo en el Pensamiento Latinoamericano: Eugenio María de Hostos y Augusto Salazar Bondy, en Agora Philosophica. Revista Marplatense de Filosofía, N ${ }^{\circ}$ 19-20, Vol. X, 2009. (pp. 8-34). [En Línea]. Disponible en: $<w w w$.agoraphilosophica.com.ar $>$. Nótese que dicho estudio analiza principalmente la obra Bartolomé o la Dominación, lo que igual tomamos en cuenta para referir el marco del concepto de labor destructiva del pensamiento de Augusto Salazar Bondy. 
sable de precisar nuevas categorías" temáticas y metodológicas en el tratamiento de las ideas latinoamericanas. Lo mismo para una visión incorporadora de corrientes e ideas que robustecen el enfoque conceptual-constructivo de la filosofía como producción institucionalizada de ideas hacia la inculturación crítica del eurocentrismo, la superación del antimodelo paradigmático y el sentido conceptual como visión englobante de la filosofía, donde el andamiaje ideológico levanta el edificio del pensamiento latinoamericano.

La filosofía 'sin más' tiene más rigurosidad teórica, libera completamente a nuestro pensar de los elementos extraños y tan ajenos que desconfiguran el intento de encontrar algo propiamente americano; es críticamente más exigente, piensa sin agregados, lejos de los influjos de esquemas que nos vuelcan a participar de problemáticas dislocadas; el 'sin más' invita a quedarnos sólo con lo que somos como el lugar más lejano donde podemos llegar. Debemos posicionarnos sin mayores prejuicios ante una historia que nos ha desfavorecido, por tanto así accederemos de manera paulatina a la mismidad que nos compete, evitando engaños ideológicos que pueden introducirse aun con la etiqueta o la marca de la liberación. De esta forma se percibe mejor el influjo ideológico de Salazar Bondy para llevar a cabo su programa de depuración cultural. La pregunta de si existe o no una filosofía en América se torna superflua y hasta casi insensata, cuestión que simplemente está demás, en la línea de un chauvinismo filosófico étnico-continental.

Ahora bien, ¿estarán las ideas de Zea libres de elementos enajenantes? ¿No se estará orientando con su análisis hacia un repliegue normalizado que evita los problemas más radicales de la filosofía y que quizás sea esa nuestra no asumida 'identidad'? Sin duda no soslaya la necesidad destructiva, pero presenta ciertas reticencias, quizás por ello la desarrolla más ampliamente. La finalidad misma del libro parece querer liberarse de la confrontación. Probablemente le preocupa delimitar la tarea destructiva al interior de una recta promoción sociocultural que no aumente el conflicto con la institucionalidad, aun cuando sea más exigente para respaldar una filosofía de la acción. Si hay una labor destructiva, concientizadora y transformadora, se trata eminentemente del pensar que se sobrecoge ante la dramática subordinación e indignidad sufrida, provocando cambios revolucionarios si es necesario. Por 
tanto, desde su visión, la centralidad de la filosofía se encuentra en la filosofía misma, como una autorreferencia al quehacer de su propio ámbito esencialmente teórico-fundamental, una teoría especulativa que precede la acción, un lugar donde la filosofía no se desborda ni colapsa ante la realidad.

Zea se opone al enfrentamiento polarizado de una América frente a los grandes poderes mundiales que la condenan a la miseria. Pero esta postura sugiere más bien la idea de una incuestionada compatibilidad y aceptación 'sin más' de toda influencia externa, algo que visto desde el curso de instauración de una mega-economía mundial, presenta serios peligros para la pretendida autenticidad del filosofar. ¿Nos lleva acaso a mirar pasivamente la contingencia histórico-cultural sin asumir posturas que pongan en peligro el statu quo de la filosofía? ¿Apunta a mantenerla en la comodidad dentro del sistema imperante, o al menos en los círculos academicistas que gozan de una buena inserción en los modelos político-educativos?

Partir de la autosuficiencia de razón y no desde la inter-acción con el mundo se asemeja a cierto modo de enajenación que da la espalda al fenómeno de nuestra híbrida identidad americana. Tal vez Zea no explicita la dirección del 'sin más', evitando la 'alienación-alienación' de la copia (consciente o inconsciente), pero dirigiéndose hacia la 'alineación-alienación' con la elite-burócrata intelectual de la sociedad de mercado.

La postura de Zea abre las puertas a un acercamiento indirecto con un conformismo ideológico. El sistema de mercado (neoliberal) empezaba en los años 60 a dar claras luces de su lógica operativa, de sus consecuencias dramáticas para las grandes masas. Es así como el 'sin más' de la filosofía latinoamericana puede ser un elemento que manifieste la implícita negociación idealista con tal evolución conformista, lo que nos hace encajar en los mecanismos e influjos ocultos de un pensamiento uniforme, al que le viene bien un estricto ejercicio puro del conocimiento. Podríamos pensar que aquel 'simplemente filosofar' de Zea se distancie de una realidad abismantemente estratificada, injusta y conflictiva, un Logos que no aplica la cuota necesaria de rebeldía y escepticismo filosófico, es decir, de una desconfianza necesaria para que los latinoamericanos se hallen a sí mismos en medio de lógicas 
que exigen su pasividad e in-conciencia para consumar la manipulación de los poderes mundiales, arraigados en los sistemas financieros y expresados en todos los estratos culturales: los Estados coludidos con el sector privado, la corrupción política, las cofradías elitistas de la religión y la universidad que intercambian privilegios mutuos en función de las grandes cúpulas de poder. Este esquema nos saca del ángulo humano que nos permite desentrañar tales estructuras dominantes, tarea que emerge desde la amenaza hacia la implicación vital del filosofar, con lo que no pierde, sino que representa su sentido estricto.

Tomando en cuenta lo anterior, Salazar Bondy se inserta de forma más genuina en el curso de la filosofía misma, invitando a destruir y a liberar su curso, a recrear aquello que hemos transformado en 'extraño' para todo nuestro entorno y que nos hace incomprensibles para un cierto (y mayoritario) sector (popular) y accesible a otro (minoritario pero empoderado) sector (privilegiado).

Tal vez no se trate de empezar de cero, pero no podemos soslayar que el asumir creativamente la condición existencial es un acto destructivo y autodestructivo de nuestras propias categorías que incomunican con el contexto más próximo e impiden re-crearnos. Tomar en consideración las categorías económicas no lo hace próximo a reducir filosofía a un problema financiero, sino que se abre como autoanálisis profundo que nos ubica radicalmente afectados por las super-estructuras. Es más bien romper con los propios supuestos, mistificaciones, convicciones pre-claras, proyectos teleológicos, fortalezas y fundamentos que sostienen nuestro papel en la discusión sobre la identidad de la filosofía. Comprender el significado de la época y sus signos nos lleva a salir del monólogo especulativo que se torna utilitario y alienante. Seguir teorizando 'constructivamente' esta situación es legitimar (y promover) la enajenación intelectual que se establece ocultando un (con)vivir que irrumpe la existencia y el pensar.

El carácter destructivo, tal como lo señala Salazar Bondy, comienza por nosotros mismos, por someter a crítica la labor y el rol que hemos ganado o pretendemos lograr, algo que tiende a postergarse. No es asunto de culpar a Zea ni a nadie de sus reticencias hacia la razón destructiva, menos aún de sus precauciones o miedos; tampoco son condenables quienes aún hagan esfuerzos por mantener (o entronizar) 
la normalidad tranquilizadora del análisis epistémico de la realidad. El filosofar latinoamericano, en identidad destructiva, podría volver sobre su originariedad si se encamina a ser un pensamiento que no se engañe en reflejos propios o esquemas que se ha hecho de sí mismo: la obsesión analítica e historicista que comporta seguir el modelo autorreferente del control de lo real, desde la distancia cada vez mayor de lo popular y de las atrofias político-vitales que nos pertenecen en su conjunto. El llamado de Salazar Bondy es a confrontar la sorda palabra filosófica que no logra traducir las voces indescifrables por momentos, pero cargadas de la interpelante situación americana que grita desgarrada con multiplicidad de registros emergentes.

La destrucción no es un método permanente para la superación de la mediocridad reflexiva; es otra temporalidad mutable que expresa la esencia del pensar crítico, asumiendo modalidades propias del acceder filosófico a las circunstancias ineludibles del ser-latinoamericano. En síntesis, el carácter destructivo exige no certificar 'sin más' las corrientes subyacentes (aun cuando las critiquemos exhaustivamente) desde las que se mueven nuestras convicciones, esa paz incierta e impredecible del filosofar. Porque la inautenticidad relativizada que intentó el 'sin más', acentuó su propia enajenación del devenir histórico, instalándose en la trinchera de la especulación determinante que oculta su propia condición, la del vivir simplemente en nuestro mundo.

\section{Bibliografía}

ARPINI, Adriana, El historicismo. Una alternativa metodológica para la historia de las ideas latinoamericanas, en Otros Discursos: Estudios de Historia de las Ideas Latinoamericanas, Facultad de Ciencias Políticas y Sociales, Universidad Nacional de Cuyo, Mendoza, 2003, 17-44.

La polémica entre Augusto Salazar Bondy y Leopolodo Zea. Una revisión del historicismo en América Latina, en Otros Discursos: Estudios de Historia de las Ideas Latinoamericanas, Facultad de Ciencias Políticas y Sociales, Universidad Nacional de Cuyo, Mendoza, 2003, pp. 45-70.

Utopía y Humanismo en el Pensamiento Latinoamericano: Eugenio María de Hostos y Augusto Salazar Bondy, en Revista Agora Philosophica. Revista Marplatense de Filosofía, N $19-20$, Vol. X, 2009. (pp. 8-34). [En Línea]. Disponible en: <www.agoraphilosophica.com.ar>.

CERUTTI, Horacio, Filosofía de la Liberación Latinoamericana, Fondo de Cultura 
Económica, México, 2006.

Filosofar desde Nuestra América, publicaciones de la Universidad Autónoma de Nayarit, en Revista Virtual de Filosofía Latinoamericana. [En línea]. Disponible en <http://www.olimon.org/uan/cerutti2.pdf>.

FORNET-BETANCOURT, Incidencia de la Teología de la Liberación en la filosofía latinoamericana, en Revista de Ciencias Sociales y Humanidades, $N^{\circ}$. 78, 2000, págs. 679-702.

De la significación de la filosofía latinoamericana para la superación del eurocentrismo, Revista de Filosofía Universidad del Zulia, Centro de Estudios Filosóficos Adolfo García Díaz, № 65, 2010-12, pp. 7-19.

SALAZAR BONDY, Augusto, ¿Existe una filosofía de nuestra américa?, Siglo XXI Editores, México, 1968.

Augusto, Bartolomé o de la dominación, Ciencia Nueva, Buenos Aires, 1974.

SANTOS HERCEG, José, ¿Qué se dice cuando se dice filosofía latinoamericana?, en Revista de Filosofía de la Universidad de Chile, Volumen 68 (2012), pp. 65-78.

Uniforme, Eurocéntrica y Conservadora. Un perfil de la enseñanza universitaria de la Filosofía en Chile, en Cuadernos CEPLA № 19 (2012), pp. 92-135.

ZEA, Leopoldo, La Filosofía Americana como Filosofía sin más, Siglo XXI Editores, México, 2010.

\section{Consultas y Fuentes en Internet}

MIRANDA REGINA, JESUS EURICO, Filosofía Latinoamericana. Disponible en: <http://www.robertexto.com/archivo13/filos_latinoam.htm>.

NAVARRO, KARLOS, El pensamiento latinoamericano: su historia y perspectivas. Disponible en: <http://www.euram.com.ni/pverdes/articulos/karlos_navarro. htm>.

MERCURIO, D. E. (miércoles 31 de agosto de 2011), emol.cl. Disponible en: $<$ http://www.emol.com/noticias/nacional/2011/08/31/500735/arturo-martinez-culpa-a-los-profesores-de-filosofia-por-violencia-en-las-marchas.html>. 